\title{
("ting
}

\section{NOVAS PERSPECTIVAS NOS ESTUDOS LEXICOGRÁFICOS: A ECOLEXICOGRAFIA E AS PALAVRAS ECOLÓGICAS}

\author{
Davi ALBUQUERQUE ${ }^{1}$ \\ Universidade Federal de Goiás - UFG - GO \\ (albuquerque07@gmail.com)
}

\begin{abstract}
Resumo: $O$ presente artigo tem como objetivo apresentar a Ecolexicografia como uma nova perspectiva para os estudos lexicológicos e lexicográficos. Isso ocorre pelo fato desta disciplina propor uma estrutura diferenciada de verbete, ou seja, da microestrutura, e também caracterizar a importância e o poder das palavras ecológicas e não ecológicas tanto para o falante, quanto no sistema linguístico. Assim, neste texto, após uma introdução sobre a Ecolinguística, será apresentada a Ecolexicografia, em (1); para em (2) se discutir as palavras ecológicas e não ecológicas; em (3), serão elaboradas algumas propostas de pesquisa em Ecolexicografia; finalmente, em (4), serão tecidas as considerações finais.
\end{abstract}

Palavras-chave: lexicografia; ecolinguística; ecolexicografia.

Abstract: This paper aims to present ecolexicography as a new perspective for lexicological and lexicographic studies. This occurs since this new discipline proposes a differentiated structure for word entry, in other words, for the microstructure, and also characterizes the importance and power of ecological and non-ecological words for both the speaker and the linguistic system. Thus, in this text, after an introduction on Ecolinguistics, ecolexicography will be presented, in (1); in section (2), it will be discussed ecological and non-ecological words; in (3), some ecolexicography research proposals will be elaborated; finally, in (4), the final considerations will be made.

Keywords: lexicography; ecolinguistics; ecolexicography

Resumen: El presente artículo tiene como objetivo presentar la ecolexicografía como una nueva perspectiva para los estudios lexicológicos y lexicográficos. Esto ocurre por el hecho de que esta disciplina propone una estructura diferenciada de verbos, es decir, de la microestructura, y también caracterizar la importancia y el poder de las palabras ecológicas y no ecológicas tanto para el hablante, como en el sistema lingüístico. Por lo tanto, en este texto, después de una introducción a la ecolingüística, se presentará a ecolexicografía en (1); para (2) discutir las palabras ecológicas y no ecológicas; (3), se elaborarán algunas propuestas de investigación en ecolexicografía; finalmente, en (4), se tejen las consideraciones finales.

Palabras clave: lexicografía; ecolinguística; ecolexicografía.

\section{INTRODUÇÃO}

A concepção da Ecolinguística como disciplina data da década de 1970, com o linguista Einar Haugen (1972), que a definiu como o estudo das relações entre língua e meio ambiente. Esta abordagem vem sendo refinada por seus praticantes ${ }^{2}$

\footnotetext{
${ }^{1}$ Doutor em Linguística pela Universidade de Brasília. Membro do Núcleo de Estudos de Ecolinguística e Imaginário (NELIM) da Universidade Federal de Goiás (UFG)

2 Optamos pelo emprego deste termo pelo fato de que o linguista, ou cientista, que adota uma postura ecológica/ ecolinguística simplesmente não o faz apenas como uma obrigação teórica e acadêmica,
} 


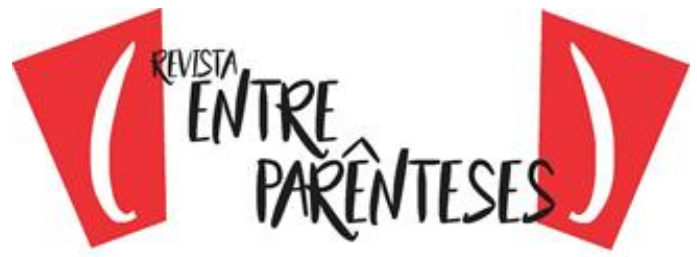

nas últimas décadas. Assim, a Ecolinguística apresenta diversas teorias, ramificações, metodologias e faz interface com diversas áreas do conhecimento e da Linguística, destacando-se, entre elas, a Ecolexicografia.

Todavia, mesmo a Ecolinguística sendo elaborada como uma alternativa, bem como uma crítica, a certas práticas vigentes de nossa sociedade, como: a visão de mundo atual de nossa sociedade relacionada à globalização e seus malefícios a indivíduos, a grupos de indivíduos e a todas as espécies; a destruição de todo tipo de diversidade (linguística, cultural, étnica, religiosa, biológica etc.); a desvalorização da vida e do meio ambiente; a importância apenas nos aspectos econômicos da vida em sociedade, em detrimento das demais relações humanas, animais e ambientais etc., ainda assim ela continua sendo mal vista ou até desconhecida por grande parte dos pesquisadores.

Desde seu surgimento, ela foi considerada como uma subárea da Linguística, relacionada à Linguística Aplicada ou à Crioulística. Atualmente, há um consenso entre os seus praticantes de que a Ecolinguística é uma ciência independente, sendo de caráter multidisciplinar (COUTO, 2013, 2015), por ser formada a partir de várias disciplinas, podendo fazer uso de diferentes suportes teórico-metodológicos (ALBUQUERQUE, 2015; COUTO, 2018a), ou até mesmo transdisciplinar (FINKE, 2014, 2017).

A Ecolinguística está relacionada com várias disciplinas, como: a Psicologia, especialmente a Psicologia Social; a Biologia, a Ecologia Biológica, a Ecologia Filosófica e a Ecologia Social, sendo que estas são a base teórico-filosófica da disciplina; as Ciências Cognitivas, que fornecem subsídios metodológicos; o Ecoletramento, também um suporte teórico à disciplina; a Arqueologia, a História, entre outras.

A Ecologia Biológica, que estuda as redes de interações entre os organismos dentro dum ecossistema (ODUM, 1971, p. 8). Já o ecossistema consiste nas interações entre os organismos (os indivíduos) numa determinada área, levando

mas vê o mundo de uma outra maneira, bem como a pratica tanto dentro quanto fora do âmbito acadêmico. 


\section{("tither}

em consideração seu meio ambiente (o mundo). Essas interações podem se dar tanto entre indivíduo-mundo, quanto entre indivíduo-indivíduo.

A Ecologia Filosófica, principalmente a Ecologia Profunda (chamada de ecofilosofia ou ecosofia), foi proposta pelo filósofo norueguês Arne Naess (19122009). Em Naess (1973), há uma espécie de manifesto do movimento, distinguindo a 'ecologia profunda', que vai à raiz dos problemas, sem subterfúgios e sem concessão à ganância econômica, da 'ecologia rasa', que defende o meio ambiente até onde essa defesa não contraria interesses econômicos. Entre as ideias pertinentes à Ecolinguística estão as seguintes: a defesa de qualquer tipo de vida, de todos os seres, de qualquer maneira; o estudo ecológico deve ser um misto do descritivo com o prescritivo, porém por meio de recomendações, não obrigações, e pela 'intervenção em defesa da vida' (NAESS, 1989).

A Ecologia Social, de Murray Bookchin, também possui ligação com a Ecolinguística ao defender a ideia de que grande parte dos problemas ambientais e ecológicos é de base social, ou seja, criados por nossa sociedade (BOOKCHIN, 1993). Portanto, cabe à sociedade resolvê-los, se quiser continuar sobrevivendo. Outra ideia interessante de Bookchin é que a 'cultura' provém da 'natura', sendo que isto o ecolinguista deve ficar atento e saber diferenciar as relações e os elementos que fazem parte de uma ou de outra.

Como resultado da adoção das perspectivas ecológicas descritas acima pela Ecolinguística, esta disciplina acaba por encarar a língua como interação, procurando estudar tais interações dentro de um ecossistema específico, de acordo com a escolha do investigador, observando principalmente: o tamanho desta comunidade/ ecossistema, pois ela deve ser reduzida para o observador estudá-la e também interagir com ela, isso é o chamado 'minimalismo empírico' (NASH, 2011, 2013; ALBUQUERQUE, 2015); a capacidade de interação e inserção do observador/ investigador no ecossistema, já que para conhecê-la melhor ele deve começar a fazer parte dela, isso é conhecido como 'trabalho de campo ecolinguístico' (NASH, 2011, 2013; ALBUQUERQUE, 2015); observar a tríade ecolinguística dentro da comunidade, são os elementos: língua $(L)$, povo $(P)$ e território $(T)$, dos quais se derivam três ecossistemas, a saber: o Ecossistema Natural da Língua, Ecossistema 


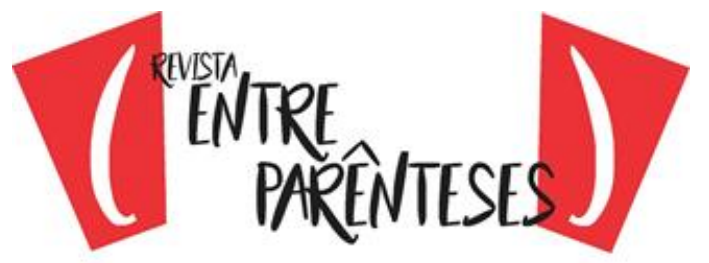

Mental da Língua e o Ecossistema Social da Língua, bem como um Ecossistema Integral da Língua, que une os três ecossistemas linguísticos anteriores (COUTO, 2013, 2015).

Ainda, a Ecolinguística estuda as interações comunicativas, analisando os aspectos ecológicos e sistêmicos destas, por meio da chamada ecologia das interações comunicativas.

Ademais, vale ressaltar que a Ecolinguística distingue duas posturas para o estudo ecológico das línguas. A primeira se preocupa com as relações entre as línguas, e as línguas com o meio ambiente. A segunda investiga as inter-relações existentes em uma língua. Esta distinção foi elaborada inicialmente por Makkai (1993), que propôs a terminologia de 'linguística exoecológica' para a primeira, e 'linguística endoecológica' para a segunda. Couto $(2007,2013,2015)$ em sua teoria ecolinguística, a Linguística Ecossistêmica, também adota a distinção de Makkai (1993). Outro linguista, Calvet (1999) faz essa mesma separação, porém chama de 'macrolinguística' e 'microlinguística'. Essa exoecologia linguística estuda as relações entre as línguas, entre língua e seus falantes, e entre língua-território. Já a linguística endoecológica dedica-se ao sistema da língua ou aos níveis de análise, com isso é possível falar de um 'ecossistema morfológico' (BUNDSGAARD e STEFFENSEN, 2000), de um 'ecossistema fonológico' (COUTO, 2018b), ou até mesmo há investigações a respeito da 'ecologia da gramática' (STEFFENSEN, 2008) e da 'ecologia do texto' (MEY, 2016).

Como tanto a Ecolinguística, quanto a Ecolexicografia são disciplinas recentes e ainda em desenvolvimento, o número de conhecedores e/ou praticantes é reduzido, mesmo com a atualidade de se modificar a visão de mundo perniciosa que nossa sociedade apresenta e a urgência de se cuidar do meio ambiente, sendo que este é apenas um dos três grandes níveis em que a Ecolinguística procura atuar (FILL e PENZ, 2017, p. 441).

De acordo com Fill e Penz (2017, p. 442), esses três níveis de atuação da Ecolinguística são: o da diversidade linguística e todas as áreas afins; as relações 'língua-discurso-meio ambiente', verificando de que maneira a língua e o discurso 


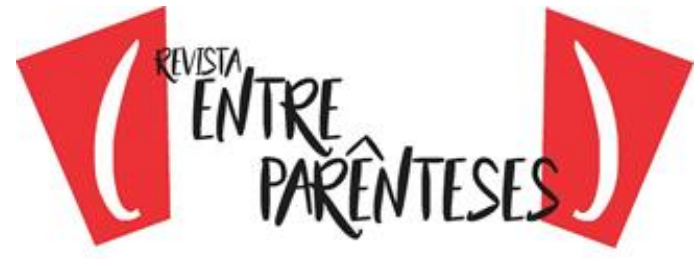

possuem papel nos problemas ambientais; a da Ecolinguística como uma ciência transdisciplinar, ou seja, os aspectos teórico-filosóficos desta abordagem.

Adotamos aqui a Linguística Ecossistêmica, que consideramos, além de uma teoria ecolinguística ou uma 'nova maneira' de se estudar a Linguagem, uma visão distinta para se observar e estudar o mundo, conforme tentamos apresentar nesta breve apresentação. Para o leitor saber mais a respeito desta proposta, bem como da terminologia distinta que ela possui, que não poderemos delimitar por questão de espaço, recomendamos a leitura de Couto (2007), que se trata do primeiro manual de Ecolinguística escrito em português, e Couto (2013), em que se encontra a Linguística Ecossistêmica detalhada.

Após esta introdução à Ecolinguística, consideramos importante discorrer a respeito da origem e da estrutura do presente texto. Primeiro, este artigo se trata dos resultados iniciais de uma pesquisa independente realizada pelo autor, que futuramente objetiva expandi-la, transformando-a num projeto formalizado pondo-a em prática em instituições de Ensino Superior e dialogando com diferentes grupos de pesquisa. Segundo, sobre a estrutura, na seção (1), a seguir, a base teórica da Ecolexicografia será exposta; em (2), serão discutidas as palavras ecológicas e não ecológicas, como identificá-las e suas ações no mundo; em (3), serão expostas algumas sugestões de pesquisa em Ecolexicografia; em (4), serão tecidas as considerações finais.

\section{A ECOLEXICOGRAFIA}

O termo 'ecolexicografia', conforme já citado, foi proposto primeiramente por Sarmento (2000). Da mesma maneira, o autor desenvolveu a proposta ecolexicográfica em publicações posteriores (SARMENTO, 2002, 2005), tal como forjou os termos das subáreas relacionadas, a saber 'ecolexicologia', 'ecoterminologia' e 'ecoterminografia' (SARMENTO, 2005 p. 92).

Alguns ecolinguistas desenvolveram ou vêm desenvolvendo investigações sobre o léxico, porém, apesar de tais investigações estarem relacionadas ou contribuírem com a Ecolexicografia, não fazem parte desta de maneira específica. 


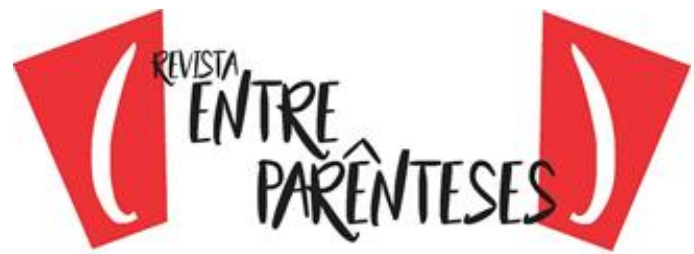

Esses trabalhos são em duas áreas distintas. A primeira trata-se do emprego do léxico e de mudanças semânticas relativos à temática ecológica, pertencentes às áreas de Análise do Discurso Ecológica. Análise do Discurso Ambiental e da Linguística Ecocrítica, destacando-se os estudos dos discursos mediáticos e ecológicos, como em Harré, Brockmaier e Mühlhäusler (1999), Alexander (2009), Stibbe $(2012,2015)$, entre outros. A segunda, são estudos de emprego/seleção lexical, terminológica e gramatical, bem como suas relações com a visão de mundo dos falantes e o grau de fragmentação existente nos sistemas linguísticos, como em Chawla (1991), Goalty (1996, 2017), Ferreira (2000, 2002), Halliday (2001 [1990]).

Finalmente, os trabalhos de Wilhelm Trampe são de interesse pelo fato de o autor ter focado sua pesquisa, no decorrer de décadas ${ }^{3}$, nas estratégias de 'eufemização' em diferentes gêneros textuais, principalmente dicionários, tanto para o mundo anglófono, como germanófono. Albuquerque (2018a) dá continuidade à revitalização da Ecolexicografia, elaborando uma reformulação da teoria e subsídios para uma ecometalexicografia, bem como apresenta contribuições da disciplina à Lexicografia Pedagógica, também analisando dicionários escolares (ALBUQUERQUE, 2018b). Com isso, enfatizamos que enquanto a Ecolinguística apresenta um desenvolvimento maior e se encontra em vias de se estabilizar e já é reconhecida como disciplina ou uma ciência distinta em vários países e universidades pelo mundo, a Ecolexicografia ainda necessita ser refinada, expandida e debatida pelos cientistas das áreas afins ${ }^{4}$. Este texto é um passo e uma tentativa de contribuição nesta área.

A Ecolexicografia pode ser encarada como uma ciência, dedicada à elaboração de obras ecolexicográficas; uma técnica, que se preocupa a análise de macroestruturas e microestruturas com o aporte ecolinguístico, ou seja, a Metaecolexicografia; e, uma área de reflexões que busca responder uma série de questões sobre os saberes e os fazeres ecolinguísticos e ecolexicográficos.

\footnotetext{
${ }^{3}$ Para uma bibliografia das pesquisas de Trampe, ver Trampe (2017, p. 325).

${ }^{4}$ Para um detalhamento da proposta ecolexicográfica, há somente o texto de Sarmento (2005). Para uma discussão atual, recomendamos as referências citadas no texto de Albuquerque (2018a, 2018b).
} 


\section{("Wîtrer}

Ao ser encarada como uma área da Ecolinguística, a Ecolexicografia tem como objetivos os mesmos três níveis mencionados anteriormente (FILL e PENZ, 2017), já que em seus aspectos teóricos procura responder uma série de questões, principalmente relacionadas ao papel que as palavras podem assumir em nosso mundo e quais são os elementos ecológicos existentes nas línguas, como estes influenciam a visão de mundo do falante, como modificam o mundo, como podem ser identificados, analisados, divulgados etc.

Desta maneira, a Ecolexicografia como ciência procura fornecer subsídios para o ecolexicógrafo elaborar tanto dicionários, quanto definições distintas do que a Lexicografia vem oferecendo até o momento. Entre as contribuições da ecolexicografia, estão: uma nova maneira de se enxergar o mundo (que é a visão ecológica de mundo, auxiliada principalmente pelo Ecoletramento) e as palavras; tornar os falantes conscientes do poder que as palavras têm tanto para o próprio falante, quanto no mundo; chamar atenção e oferecer maneiras de identificar os elementos ecológicos nas línguas; propor uma nova estrutura de verbete e definição (ver fig. 1 mais abaixo); enfatizar mais os efeitos e resultados no mundo de uma palavra nas definições.

Ao se preocupar com as palavras no mundo, a Ecolexicografia, como ciência, atua no primeiro nível de objetivo da Ecolinguística, enquanto a Ecolexicografia como técnica atua no segundo nível, disponibilizando ferramentas para análise de dicionários à luz da Ecolinguística, preocupando-se mais com os efeitos e resultados que uma definição específica de uma palavra pode causar nos indivíduos ou no mundo.

O que foi afirmado acima está em consonância com o Ecoletramento, que possui relação próxima com a Ecolexicografia, já que aquele trata do desenvolvimento, principalmente por meio do ensino e da educação, da capacidade dos indivíduos de ter um "pensamento favorável à desconstrução do paradigma antropocêntrico que carateriza as sociedades ocidentais e as suas consequências mais diretas", sendo a principal delas a "do homem como legítimo explorador do meio natural em seu proveito" (RAMOS e RAMOS, 2013, p. 17). O desenvolvimento dessa capacidade mencionada só é possível ser alcançado por meio de mudanças de 


\section{("Wîtrer}

mentalidade e de atitudes, por isso a importância do ensino formal e da educação (dentro e fora da escola) que procure estimular, modificar e tornar os indivíduos conscientes.

Em Sarmento (2005), o autor elenca uma série de proposições e questionamentos da Ecolexicografia, as quais comentaremos abaixo. A seguir, debateremos primeiro as proposições, pois elas apresentam alguns esclarecimentos teóricos a respeito da Ecolexicografia, expõe de maneira sucinta o que ela não é e propõe uma nova estrutura de verbete, o verbete ecolexicográfico. Deixaremos para a seção seguinte, a seção (2), para um levantamento das questões que a Ecolexicografia procura responder, pois é a partir destas perguntas que surgem as temáticas das palavras ecológicas e não ecológicas, bem como o poder delas no mundo.

As proposições iniciais procuram expor de maneira didática o que é e o que não é a Ecolexicografia, assim é enfatizado que a Ecolexicografia não trata da elaboração de dicionários de Ecologia ou de termos ecológicos, mas consiste num trabalho de reflexão e elaboração dos verbetes dos dicionários pensando nos efeitos e resultados que cada lexema traz aos indivíduos (espécie interagindo dentro do ecossistema) e para o planeta (o ecossistema). Desta maneira, também não se relaciona diretamente com a Terminologia e a Terminografia.

Vale lembrar que o radical eco- é delimitado, estando relacionado com a Ecologia Biológica e, consequentemente, com a lógica e os efeitos desta, não sendo empregado de maneira aleatória, ideológica ou politicamente correta.

Ademais, a Ecolexicografia não descarta todos os avanços alcançados pela Lexicografia, ao contrário, ela visa contribuir com esta, principalmente na microestrutura, já que oferece subsídios para se repensar a estrutura dos verbetes, com novas ideias e elementos, da mesma maneira que aponta novos usos para o dicionário em sala de aula (ensino mais holístico e menos antropocêntrico; apresentar uma nova maneira de pensar e agir, a VEM; Ecoletramento etc.) e fornece novas ferramentas para metalexicógrafos realizarem suas análises.

Finalmente, as últimas proposições da Ecolexicografia afirmam que ela, como uma disciplina que tem suas origens na Lexicografia e na Ecolinguística, 


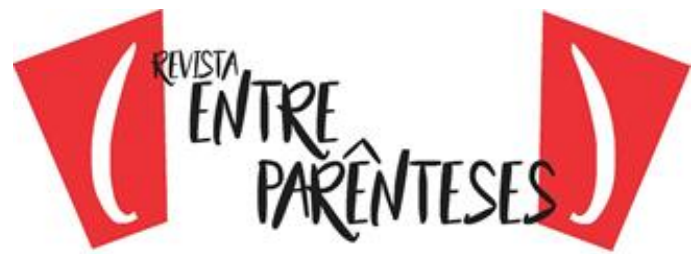

mantém e expande as relações com as demais áreas que possuem algum interesse compartilhado com a Lexicografia, a saber: Linguística Computacional, Linguística de Corpus e Linguística Aplicada (DURAN e XATARA, 2007).

Outra área de interface da Ecolexicografia é a Pragmática e, desta maneira, diferencia-se da Lexicografia, já que naquela a tarefa do ecolexicógrafo, além de "observar, descrever e explicar palavras e expressões vistas a partir do viés eco", é de "tomar posição sobre os efeitos e resultados lógicos que elas desempenham. Ou seja, estamos trabalhando não apenas com o significado de palavras e expressões, mas a questão dos seus usos (...)" (SARMENTO, 2005 p. 93).

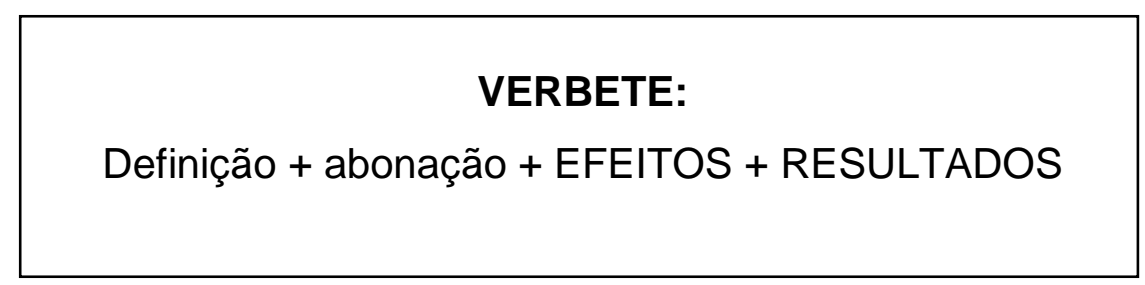

Figura 1. Microestrutura do verbete ecolexicográfico Fonte: Adaptado de Sarmento (2005, p. 91)

Sobre a estrutura do verbete ecolexicográfico, a contribuição deste campo à Lexicografia é nos 'efeitos' e 'resultados' na microestrutura. Para a definição em Ecolexicografia, recomenda-se uma definição mista que faça uso das informações da definição lexicográfica somadas às da definição enciclopédica ${ }^{5}$. Nas abonações, sugere-se ao ecolexicógrafo fazer uso de exemplos inventados quando este é falante da língua materna e de abonações retiradas de diferentes corpora para que possa haver uma comparação entre os diferentes usos e significados ${ }^{6}$.

Sobre os 'efeitos', Sarmento (2005) lista cinco principais e suas respectivas siglas para ser empregue no verbete, que são eles: criativo (EC), mantenedor (EM),

\footnotetext{
${ }^{5}$ Sobre os diferentes tipos de definição, entre eles a definição mista, que este trabalho emprega e sugere, por considerarmos a mais adequada à Ecolexicografia, ver Lehmann e Martin-Berthet (1998) e Pontes (2009).

${ }^{6}$ Para diferenciação entre tipos de exemplos e abonação que é empregada neste trabalho e, da mesma maneira, é importante para a Ecolexicografia, que acaba por fazer uso de ambas, ver Humblé (2001), Welker (2004) e Svensen (2009).
} 


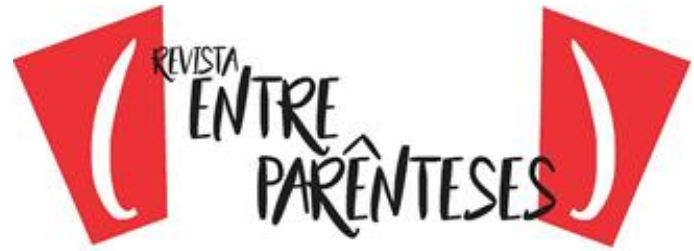

fortalecedor (EF), enfraquecedor (EE) e destrutivo (ED). Assim, cabe ao ecolexicógrafo descrever os efeitos que o emprego daquela ideia ou a prática dela têm nos indivíduos e no mundo. Ex. praga, EE e ED, nome dado a seres vivos das famílias insecta ou gramínea. Os efeitos são enfraquecedores e destrutivos simplesmente pelo fato de apontar as várias espécies somente como más e predadoras, o que possibilita sua matança que, algumas vezes, causa desequilíbrio no ecossistema.

Já os 'resultados' cabe ao ecolexicógrafo pensar o lexema de diferentes maneiras e suas consequências: como é analisado mentalmente pelos falantes; quais seus usos; quais usos poderia ter; quais relações com outros lexemas, ideias e práticas. Assim, as ferramentas de que dispõe são as seguintes: a lógica formal e seu binário de opostos (ex. biodiversidade $x$ extinção; heterogeneidade $x$ homogeneidade); a dialética e o ternário de confluências (ex. lixo > poluição, contaminação > reciclagem, compostagem, benefícios (ao meio ambiente); morte > malefícios, dor > natureza (morte natural), ciclos, alimento, vida); gradiente e as escalas, continua e tipos; dialogismo.

Um exemplo de ecoverberte, ou verbete ecolexicográfico, elaborado por nós e com base no que foi exposto aqui se encontra ao final deste artigo.

Na seção (2) a seguir, apresentaremos as questões que a Ecolexicografia procura responder por meio de sua investigação, de qual maneira estas estão relacionadas às palavras ecológicas e não ecológicas, bem como a influência que tais palavras têm no mundo.

\section{AS PALAVRAS ECOLÓGICAS E NÃO ECOLÓGICAS}

A ecolexicografia além de se preocupar com as definições e usos das palavras, por sua ligação com a Lexicologia e Lexicografia, visa também investigar os efeitos que uma palavra tem nas pessoas e no mundo, ou seja, como a língua afeta o ecossistema de acordo com o emprego e o dizer do falante, e da mesma maneira busca avaliar os resultados do emprego dessas palavras. 


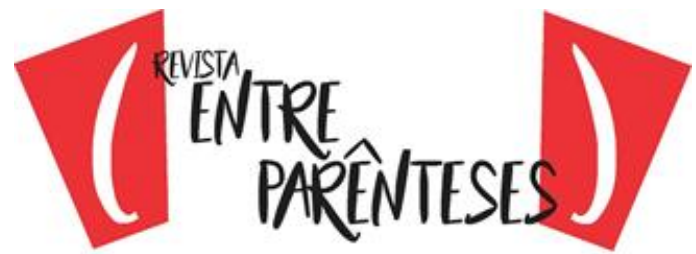

Isto já foi apontado anteriormente por Halliday (2001 [1990]) como um tópico futuro e importante para a Linguística, e retomado até os dias de hoje pela Ecolinguística, que seria o impacto das questões e usos linguísticos sobre o meio ambiente, principalmente em relação à oposição 'holismo x fragmentação', o primeiro sendo elementos ecológicos e o segundo, não ecológicos do sistema linguístico, ou seja, há elementos linguísticos que são ecológicos, pois são marcados por certo grau de integração, enquanto há outros que não são ecológicos ao promover a fragmentação.

Partindo dessas informações é que surgem as duas principais questões da Ecolexicografia (SARMENTO, 2005, p. 94):

- Qual o papel das palavras no nosso Mundo? E, como uma palavra pode criar, manter ou destruir um Mundo? ${ }^{7}$

Procurando responder às duas primeiras questões da Ecolexicografia com base no que vem sendo produzido atualmente na pesquisa ecolinguística, afirmamos que o papel das palavras no mundo é o mesmo da língua, ou seja, as palavras têm o principal papel de intermediar as interações indivíduo-indivíduo e indivíduo-mundo.

As palavras apresentam uma capacidade de influenciar o Mundo de acordo com o poder de três elementos: o poder do falante; o poder do meio de propagação da palavra utilizada pelo falante; o poder de dominação, persuasão ou controle sob o ouvinte. Estes três elementos não são estanques, podendo se entrelaçar a depender da situação estudada. Exemplos do primeiro elemento, o poder do falante, são casos em que políticos, famosos, a elite financeira etc. se utilizam das palavras e causam mudanças no Mundo, seguindo seus interesses. Exemplos do segundo, o poder do meio, temos a internet, a televisão, o cinema, a publicidade, entre outros, em que ao fazer uso das palavras podem fazer alterações rapidamente no Mundo e no comportamento das pessoas, basta pensarmos em 'youtubers', campanhas hollywoodianas, telenovelas, propagandas etc. Exemplos do terceiro, poder sob o ouvinte, observamos a todo momento pessoas facilmente manipuladas,

\footnotetext{
${ }^{7}$ A palavra 'mundo' aqui é sinônimo de 'ecossistema'.
} 


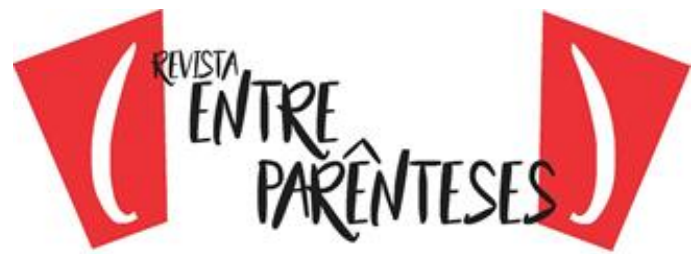

sugestionáveis ou impressionáveis, tanto por indivíduos próximos a elas, quanto por aqueles que se encontram em posse dos poderes apontados no primeiro e segundo elementos, tal sugestionabilidade deve ser investigada em cada caso, podendo estar ligada à escolaridade, ao perfil psicológico, a situações de vida, entre outras.

Daí, é possível afirmar que as palavras influenciam, sim, as pessoas e o Mundo. Com isso, são elencadas várias outras indagações que devem ser investigadas e que a Ecolexicografia procura responder:

- Como encontrar os elementos ecológicos e não ecológicos nas línguas?

- A língua influencia a visão de mundo, ou vice-versa?

- Como medir as influências da língua sobre a visão de mundo? E da visão de mundo sobre a língua?

Sobre a capacidade de se encontrar os elementos ecológicos, utilizaremos as propostas de Chawla (1991), Goatly (1996), Fill (2001) e Halliday (2001 [1990]), que fornecem subsídios ao investigador para observar quais elementos linguísticos e, da mesma maneira, quais palavras são ecológicas, pois estas se tratam de palavras que promovam o holismo, ou seja, a união entre os indivíduos da mesma espécie, de espécies diferentes, e das diferentes espécies com o mundo.

Há uma série de elementos não ecológicos já mapeados e existentes nas línguas do mundo, que levam à fragmentação, sendo eles: a separação entre agente, paciente, experienciador e instrumento, que separa o ser humano da natureza; categorização de fenômenos em processos/ coisas; separação entre humanos, animais e plantas; a causalidade, que pressupõe controle e superioridade; o sistema pronominal; a marcação de posse; expressões temporais e marcação das categorias TMA. Essa fragmentação consiste no fato de ocorrer a separação em vários níveis distintos entre o homem e o meio ambiente, tanto na língua, como na visão de mundo, separações como: humano $x$ animais, humano $x$ seres inanimados, coisas úteis para o ser humano $x$ coisas não úteis. Todavia, o investigador deve ter um cuidado, já que tais separações, mesmo sendo consideradas antropocentrismo linguístico (FILL, 2001, p. 67), sempre vão existir na língua, tanto pelo fato dela ser uma construção 


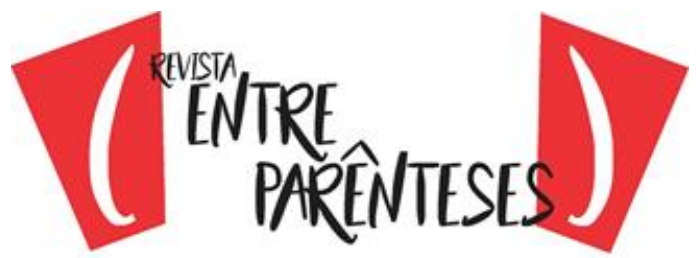

humana (refletindo os limites e possibilidades de nossa cognição), quanto pela natureza adaptativa do próprio sistema linguístico, sendo como uma memória dos estágios anteriores da língua (HALLIDAY, 2001 [1990]), apresentando, assim, certos elementos não ecológicos como possíveis frutos de uma adaptação já realizada, ou em andamento, da gramática a alguma modificação no meio ambiente, ou até a um novo meio ambiente.

Porém, ainda assim, vale lembrar que qualquer palavra ou elemento linguístico que promova a fragmentação, são chamados de não ecológicos. Ademais, poderíamos fazer uso do critério da Ecologia Profunda, também utilizado por Couto $(2013,2015)$ na Linguística Ecossistêmica, que observa se um elemento é ecológico ou não, se é bom ou ruim, em relação ao seu posicionamento diante da vida (de toda a vida em geral), assim tudo aquilo que gera harmonia, possibilita e garanta o convívio e a vida é ecológico, enquanto tudo que cause dor, separação/ fragmentação e morte não é ecológico.

Sobre a relação de língua e visão de mundo, faremos uso novamente da Linguística Ecossistêmica para explicar nosso posicionamento. Esta teoria ecolinguística parte do ecossistema e das interações, propondo o ecossistema linguístico e os três elementos basilares deste, que são a língua (L), o povo (P) e o território (T). Partindo da proposta de Couto $(2007,2013,2015)$ para representar graficamente esta teoria, temos a fig. 2 abaixo:

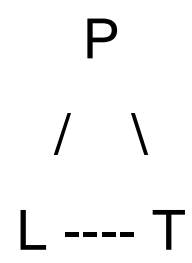

Figura 2. Os elementos do Ecossistema da Língua Fonte: adaptado de Couto (2015, p. 49)

A partir da fig.2, é possível ver que a língua $(L)$ tem relação direta somente com o povo $(\mathrm{P})$, e a relação com o território $(\mathrm{T})$, o Mundo, se dá de maneira indireta, por isso a linha tracejada. Assim, com o que foi desenvolvido nas pesquisas 


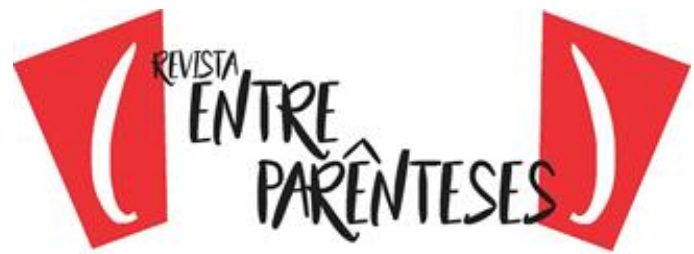

ecolinguísticas até o momento, incluindo pesquisas que relacionam a Ecolinguística com as ciências neurocognitivas, assumimos uma postura equilibrada que postula a possibilidade de influência dupla, tanto a língua influencia a visão de mundo, seguindo o caminho $L>P>T$, quanto a visão de mundo influencia a língua, seguindo o caminho reverso, $\mathrm{T}>\mathrm{P}>\mathrm{L}$.

Em relação a um critério para a medição dessas influências que vimos apontando aqui, ainda não há nenhum formulado até o momento e este é um dos questionamentos que se encontram em aberto para investigações futuras.

Dando um destaque às palavras ecológicas e não ecológicas, Sarmento (2005) propõe uma série de questionamentos a respeito delas. Primeiro, o autor as chama de 'ecopalavras' e as diferencia das 'ecoexpressões', que seriam expressões ou locuções ecológicas, análogas às palavras ecológicas. Desta maneira, tanto as ecopalavras, quanto as ecoexpressões seriam aquelas que trariam benefícios ao falante e ao ecossistema quando empregadas ou praticadas. Elas estão em oposição, podendo ora ser contrastadas com as palavras e expressões não ecológicas, que são aquelas que trazem malefícios ou prejudicam os indivíduos e/ou o Mundo.

- Como pode uma palavra ecologizar uma língua ou ser um elemento ecológico nela?

- Uma ecopalavra, ou várias delas, podem contribuir para o ecoletramento, mudança ou formação de uma nova visão de mundo?

- Quais funções uma ecopalavra possui no ecossistema? E qual poder ela tem de alterá-lo para melhor ou pior?

Podemos responder a primeira pergunta, sobre a capacidade de uma palavra ecologizar a língua, retomando o que já foi afirmado a respeito do holismo. Uma palavra é capaz de ecologizar a língua ao possuir uma natureza que promova uma consciência ou uma ação ecológica no falante, bem como que promova uma maior integração do falante com demais indivíduos, espécies ou o ecossistema, ou que possa contribuir para reduzir a fragmentação de algumas estruturas existentes no sistema linguístico 


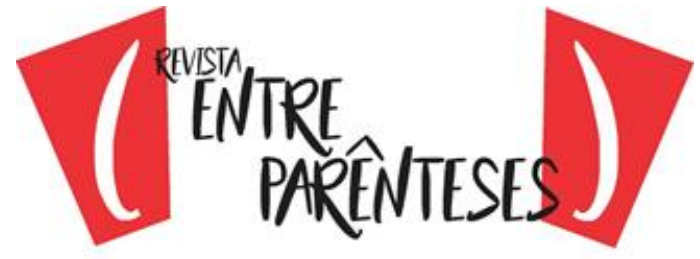

Dando sequência, as ecopalavras podem contribuir com o Ecoletramento, principalmente fornecendo ferramentas e dados dos resultados das investigações e das publicações, quando a área estiver mais estabelecida no futuro. Já para se efetuar a mudança de visão de mundo, a Ecolexicografia seguirá o caminho contrário, utilizando-se dos resultados alcançados pelo Ecoletramento e os passos que esta disciplina seguiu. Deste modo, faz-se necessário num primeiro momento a inserção das disciplinas 'Ecolexicologia' e 'Ecolexicografia' (sem esquecer da 'Ecolinguística') nos cursos de Educação e Letras para que haja a formação de professores e de ecolexicógrafos para que, num segundo momento, possa ocorrer a produção de material didático ecolexicográfico e o professor com um conhecimento de Ecolexicografia possa ensiná-la aos seus alunos. Assim, com a formação de professores, elaboração de material e ensino da disciplina é que a Ecolexicografia e as ecopalavras podem mudar a visão de mundo. Tal proposta foi elaborada por Albuquerque (2018b).

Finalmente, a ecopalavra tem a função de promover o holismo dentro do sistema linguístico e no falante, e, como foi discutido anteriormente, o poder das palavras ecológicos e tamanho que ela pode alterar ambos (o sistema e o falante). Como as ecopalavras podem alterar o sistema linguístico, o falante e o ecossistema consideramos válida a proposta dos efeitos de Sarmento (2005), sendo eles: criativo $(E C)$, mantenedor (EM), fortalecedor (EF), enfraquecedor (EE) e destrutivo (ED), pois é possível verificar nas pesquisas ecolinguísticas realizadas até o momento estes cinco efeitos como resultados das ecopalavras, sejam eles positivos ou negativos.

Há vários outros questionamentos que a Ecolexicografia traz e procura responder, porém por limitações de espaço e para não fugir do escopo deste texto, que é apresentação da Ecolexicografia e das palavras ecológicas e não ecológicas para a ecolexicografia, não as trataremos aqui, deixando para abordá-las em outra oportunidade. $\mathrm{Na}$ próxima seção, discutiremos propostas de pesquisa em Ecolexicografia.

\section{A PESQUISA EM ECOLEXICOGRAFIA}




\section{("tither}

A perspectiva de pesquisa em Ecolexicografia e propostas de projetos de investigação foram lançados inicialmente por Sarmento (2002, p. 491) o qual nos basearemos, retomando-os e desenvolvendo-os nesta seção.

Porém, antes de expormos as propostas e projetos de pesquisa em Ecolexicografia, consideramos importante 0 debate e questionamentos desta disciplina a respeito do lugar e do papel do ecolexicógrafo e de seu trabalho. Ademais, ao refletirmos e respondermos tais questionamentos da Ecolexicografia estaremos simultaneamente oferecendo propostas de pesquisa e subsídios duma metodologia. As perguntas principais que Sarmento (2005) levanta, afirmando que a Ecolexicografia visa responder são as seguintes:

- Como se pode contribuir para promover as ecopalavras?

- Como deve proceder o ecolexicógrafo diante de palavras não ecológicas?

- Qual deve ser o posicionamento do ecolexicógrafo em relação às palavras não ecológicas (descritivo, normativo, reflexivo, analítico etc.)?

A promoção das palavras ecológicas ocorre de maneira semelhante a nossas respostas na seção anterior, devendo passar por uma etapa de pesquisas, na esfera acadêmica, e assim que estiver estabilizada e com certo grau de consenso nesta esfera deve passar às esferas políticas e educacionais para que sejam promovidas discussões, recebam apoio e façam parte do ensino. Somente ao obter resultados positivos nessas esferas é que deva tentar se expandir, visando a sociedade como um todo, procurando popularizar as ecopalavras, fazendo-as parte do dia a dia das pessoas, de sua mentalidade e, assim, modificando a visão de mundo delas.

O ecolexicógrafo não deve omitir, nem se omitir, em relação às palavras não ecológicos, ao contrário, deve conduzir um trabalho semelhante ao das ecopalavras, em relação a sua identificação, estudo, definição, efeitos e resultados, diferenciando-se apenas nos aspectos educacionais e na visão de mundo que deve ser adotada. Isto está relacionado com seu posicionamento também, já que na 


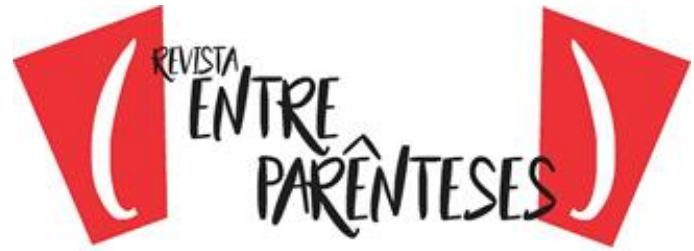

investigação ecolexicológica e ecolexicográfica o pesquisador deve recorrer aos mesmos recursos linguísticos e ecolinguísticos (e ecolexicográfico também) para estudar as palavras ecológicas e não ecológicas, porém deve ter uma postura distinta ao apontar os efeitos, resultados e as redes de interações de cada uma, o que será discutido a seguir.

Sobre a metodologia em Ecolinguística e em Ecolexicografia, é importante tecer algumas palavras, pois ela segue a perspectiva multirreferencial (ARDOINO, 1998; MARTINS, 1998; SARMENTO, 2002, p. 491) ou multimetodológica (ALBUQUERQUE, 2015; COUTO, 2018a), que se destacam por adotar, quando necessário para a análise ou de acordo com o objeto estudado, aspectos teóricos, metodológicos e/ou contribuições de outras áreas, oferecendo uma visão ampla, multifacetada, de várias perspectivas sobre o objeto, desenvolvendo uma perspectiva de rede e enfatizando os processos dos dados coletados, com a visão ecológica/ ecolinguística guiando todo os passos da pesquisa e as interpretações finais dos dados e dos resultados ${ }^{8}$.

Ademais, a Ecolexicografia, além de se desenvolver com as conquistas teóricas já alcançadas pela Lexicografia, conforme já afirmado, pode expandir a pesquisa em relação ao processo de nomeação e de formação do léxico, seja das palavras ecológicas, seja das não ecológicas, enfatizando os aspectos cognitivos e de categorização, sendo este tipo de pesquisa relacionada tanto à própria Lexicografia, quanto à Ecolinguística, principalmente na Linguística Ecossistêmica e o Ecossistema Mental da Língua. Porém, nesta seção, elaboramos apenas sugestões de pesquisas, sendo que todas elas ainda estão em aberto, já que nenhuma delas foram conduzidas ${ }^{9}$.

\footnotetext{
8 Para maiores explicações, detalhamento e aplicações dessas metodologias, ver as referências já citadas.

${ }^{9}$ Vale ressaltar que a pesquisa ecolexicográfica em andamento pelo presente autor se encontra em estágio inicial. Nesta primeira fase da pesquisa, o autor preocupar-se-á em refinar e elaborar os instrumentos teórico-metodológicos da disciplina, testando suas ideias/ resultados em algumas palavras ecológicas e não ecológicas, e apresentando esses resultados para debate e reflexão em círculos acadêmicos mais restritos (ecolinguistas e lexicógrafos) por meio de congressos e periódicos. A segunda fase do projeto será dedicada resolução dos questionamentos e problemas relacionados às palavras ecológicas e não ecológicas, conforme apresentados nesta seção e na seção anterior. Somente com a Ecolexicografia mais reconhecida, estabilizada e pratica é que o autor pretende se debruçar sobre a elaboração de verbetes ecolexicográficos.
} 


\section{("tither}

As pesquisas iniciais em Ecolexicografia devem se preocupar em listar e mapear as palavras ecológicas, de um lado, e as palavras não ecológicas, de outro. Somente estas tarefas são árduas e trabalhosas, podendo ser efetuadas de diferentes maneiras, com um ecolinguista se dedicando somente a listagem de uma ou de outra; há também o trabalho comparativo, com o ecolinguista coletando as palavras ecológicas e não ecológicas; a pesquisa pode ser feita também por uma equipe de ecolinguistas que, além das listagens, ofereceriam um mapeamento, que seria observar as relações entre as ecopalavras, entre as ecopalavras e as ecoexpressões, e, por último, entre estas e as palavras não ecológicas.

Outro campo de pesquisa em Ecolexicografia é o refinamento e desenvolvimento da teoria e metodologia ecolexicográficas, conforme já destacamos anteriormente, não são todos os questionamentos levantados nesta disciplina que já estão respondidos. Há uma necessidade, além disso, de se refinar a proposta da microestrutura; detalhar e criar critérios para a identificação das ecopalavras e de seu nível de 'ecologização'; a estrutura das ecoexpressões; observação da existência ou não de expressões não ecológicas; verificação da existência de palavras as quais não se aplicam os conceitos de 'palavras ecológicas' e 'palavras não ecológicas', o que possibilitaria a criação de um terceiro conceito, chamado por Albuquerque (2018b) de 'palavras antiecológicas'. Digno de nota é que esses estudos mais teóricos só podem ser conduzidos tendo como base 0 avanço das pesquisas com dados em Ecolexicografia.

Finalmente, as investigações e divulgação de resultados em formato de livros didáticos e listas de vocabulários, contendo as ecopalavras e ecoexpressões, devem se basear nos dois tipos de pesquisas anteriores, sendo que as deste terceiro grupo seriam mais desafiadoras, pois pressupõe não um único pesquisador ou uma equipe reduzida de áreas próximas. Esta etapa é bem maior, envolvendo profissionais de diversas áreas para auxiliar e refinar as definições das ecopalavras, identificar algumas que foram deixadas de lado, oferecer ideias e maneiras para um tratamento mais didático para a divulgação para professores e alunos.

\section{CONSIDERAÇÕES FINAIS}




\section{("tither}

No presente artigo, apresentamos a Ecolexicografia e as palavras ecológicas e não ecológicas, juntamente com uma proposta diferenciada de microestrutura que esta disciplina traz. Para tanto, foi necessário conduzir algumas explicações introdutórias sobre a Ecolinguística, disciplina relacionada à Ecolexicografia, seguidas pelos aspectos teóricos da disciplina abordada aqui, na seção (1).

Em (2), discutimos as palavras ecológicas, também chamadas de ecopalavras, e as palavras não ecológicas, e como a perspectiva ecolexicográfica pode contribuir para a Lexicografia, principalmente por apresentar uma nova visão para os estudos da linguagem, especialmente das palavras, bem como uma abordagem diferenciada.

Finalmente, outra contribuição da Ecolexicografia é que ela possui um projeto de pesquisa possível de ser realizado e que envolve a necessidade de uma equipe multidisciplinar, o que poderia ser um grande avanço para os estudos lexicográficos em geral, que além de poder desenvolver uma nova abordagem para seus estudos, ganharia bastante com os resultados de um trabalho multidisciplinar e multimetodológico, intensificando ainda mais os trabalhos e resultados que a Lexicografia já vem alcançando.

Em outras palavras, a Lexicografia ao aceitar trabalhar em conjunto com a Ecolexicografia só teria a ganhar.

\section{REFERÊNCIAS}

ARDOINO, J. Nota a propósito das relações entre a abordagem multirreferencial e a análise institucional (história ou histórias). In: BARBOSA, J. G. (org.). Multirreferencialidade nas ciências e na educação. São Carlos: Editora da UFSCar, 1998. p. 42-49.

ALBUQUERQUE, D. B. Palavras iniciais sobre a metodologia em ecolinguística. Via Litterae, v. 7, n. 1, p. 131-142, 2015.

Revisitando a ecolexicografia. In: TIMBANE, A. et al. (Orgs.) Anais do IV

Encontro Brasileiro de Ecolinguística. Fortaleza: PGL - UFC, 2018a. p. 36. 


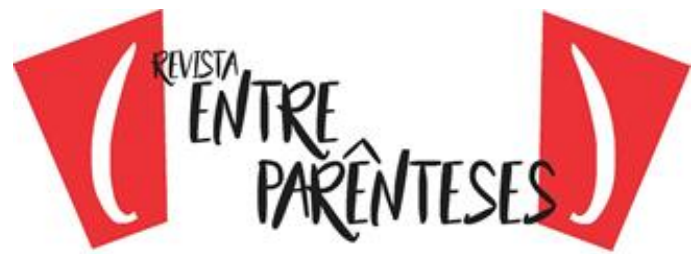

As contribuições da Ecolexicografia à Lexicografia Pedagógica. Domínios de Lingu@gem, v. 12, 2018b.

ALEXANDER, R. Framing Discourse on the Environment: A Critical Discourse Approach. New York: Routledge, 2009.

BANG, J. C.; DØØR, J. Language, Ecology and Society. A Dialectical Approach. Londres: Continuum, 2007.

BOOKCHIN, M. What is social ecology? In: ZIMMERMAN, M. E. (org.). Environmental philosophy: From animal rights to radical ecology. Englewood Cliffs: Prentice Hall, 1993.

BUNDSGAARD, J.; STEFFENSEN, S. The Dialectics of Ecological Morphology - or the Morphology of Dialectics. In: LINDØ, A. V.; BUNDSGAARD, J. (eds.). Dialectical Ecolinguistics. Three essays for the symposium 30 Years of Language and Ecology in Graz. Nordisk Institut: University of Odense, 2000. p. 8-36.

CALVET, L-J. Pour une écologie des langues du monde. Paris: Plon, 1999.

CHAWLA, S. Linguistic and philosophical roots of our environmental crisis. Environmental Ethics, v. 13, n. 3, p. 253-273, 1991.

COUTO, H. H. Ecolinguística. Estudo das relações entre língua e meio ambiente. Brasília: Thesaurus, 2007.

O que vem a ser ecolinguística, afinal? Cadernos de Linguagem \& Sociedade, v. 14, n. 1, p. 275-313, 2013.

Linguística ecossistêmica. ECO-REBEL - Revista Brasileira de Ecologia e Linguagem v. 01, n. 01, p. 47-81, 2015.

A metodologia na linguística ecossistêmica. ECO-REBEL - Revista Brasileira de Ecologia e Linguagem, v. 04, n. 02, p. 18-33, 2018 a.

Fonelogia: argumentos em prol de uma fonética-fonologia ecossistêmica. In: TIMBANE, A. et al. (Orgs.) Anais do IV Encontro Brasileiro de Ecolinguística. Fortaleza: PGL - UFC, 2018b. p. 26.

DURAN, M. S.; XATARA, C. M. Lexicografia pedagógica: atores e interfaces. D. E. L. T. A., v. 27, n. 2, p. 203-222, 2007.

FERREIRA, A. C. Não nos lixem! Eine sprachkritische Müllgeschichte (DeutschPortugiesisch). In: KETTEMANN, B.; PENZ, H. (ed.). ECOnstructing Language, Nature and Society. The Ecolinguistics Project Revisited. Essays in Honour of Alwin Fill. Tübingen: Stauffenburg Verlag, 2000. 


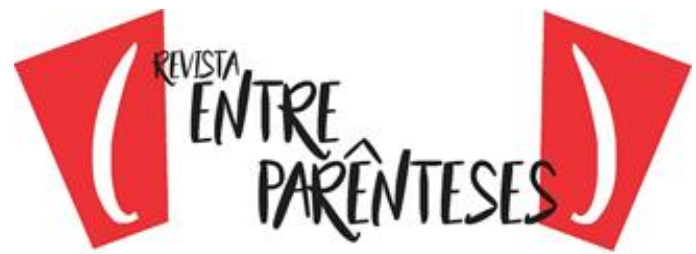

Beitrag zu einem Hassprachewörterbuch Deustsch-Portugiesisch. In: FILL, A.; PENZ; H; TRAMPE, W. (ed.). Colourful Green Ideas. Viena: Peter Lang Verlag, 2002. p. 275-298.

FILL, A. Language and ecology: ecolinguistic perspectives for 2000 and beyond. In: Graddol, D. (ed.). AlLA Review 14. Applied linguistics for the 21st century. Londres: Catchline, 2001, p. 60-75.

FILL, A.; PENZ; H. Ecolinguistics in the 21st Century. New Orientations and Future Directions. In: FILL, A.; PENZ; H. (ed.). The Routledge Handbook of Ecolinguistics. Londres: Routledge, 2017. p. 437-443.

FINKE, E. The Ecology of Science and its Consequences for the Ecology of Language. Language Sciences, v.41, p.71-82, 2014.

Transdisciplinary Linguistics. Ecolinguistics as a Pacemaker into a New Scientific Age In: FILL, A.; PENZ; H. (ed.). The Routledge Handbook of Ecolinguistics. Londres: Routledge, 2017. p. 406-419.

GOATLY, A. Green grammar and grammatical metaphor, or Language and the myth of power, or Metaphors we die by. Journal of Pragmatics, v. 25, p. 537-560, 1996.

HALLIDAY, M. A. K. New Ways of Meaning: the Challenge to Applied Linguistics. In: FILL, A.; MÜHLHÄUSLER, P. (ed.). The Ecolinguistics Reader. Language, ecology, and environment. Londres: Continuum, 2001 [1990], p.175-202.

HARRÉ, R.; BROCKMAIER, J.; MÜLHLHÄUSLER, P. Greenspeak: A Study of Environmental Discourse. London: Sage, 1999.

HAUGEN, E. The Ecology of language. Stanford: Stanford University Press, 1972.

HUMBLÉ, P. Dictionaries and Language Learners. Frankfurt am Main: Haag und Herchen, 2001.

LEHMANN, A.; MARTIN-BERTHET, F. Introduction à la lexicologie: sémantique et morfologie. Paris: DUNOD, 1998.

MAFFI, L. (ed.). On Biocultural Diversity. Linking Language, Knowledge, and the Environment. Washington/ Londres: Smithsonian Institution Press, 2001.

MAKKAI, A. Ecolinguistics. ¿Toward a New ${ }^{* *}$ Paradigm ${ }^{* *}$ for the Science of Language? Londres: Pinter Publishers Ltd., 1993.

MARTINS, J. B. Multirreferencialidade e educação. In: BARBOSA, J. G. (org.). Reflexões em torno da abordagem multirreferencial. São Carlos: EdUFSCar, 1998. p. 21-34. 


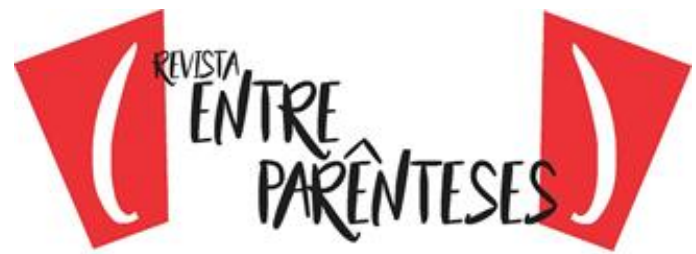

MEY, J. L. Sequencialidade. Para uma ecologia do texto. ECO-REBEL - Revista Brasileira de Ecologia e Linguagem, v. 2, n. 2, p. 4-14, 2016.

MUFWENE, S. The ecology of language evolution. Cambridge: Cambridge University Press, 2001.

Continuum, 2008.

MÜHLHÄUSLER, P. Language of environment, environment of language: a course in ecolinguistics. Londres: Battlebridge, 2003.

NAESS, A. The shallow and the deep, long-range ecology movement: a summary. Inquiry, v. 16, p. 16-100, 1973.

Press, 1989.

Ecology, community and lifestyle. Cambridge: Cambridge University

NASH, J. Norfolk Island, South Pacific: An empirical ecolinguistic case study. AUMLA - Journal of the Australasian Universities Language and Literature Association, v. 116, p.83-97, 2011.

. Insular Toponymies. Pristine Place-naming on Norfolk Island, South Pacific and Dudley Peninsula, Kangaroo Island. Amsterdam: John Benjamins Publishing, 2013.

ODUM, E. P. Fundamentals of ecology. Philadelphia: W. B. Saunders Company, 1971.

PONTES, A. L. Dicionário para uso escolar. O que é, como se lê. Fortaleza: EdUECE, 2009.

RAMOS, A. M.; RAMOS, R. Ecoliteracia e literatura para infância.: quando a relação com o ambiente toma conta dos livros. Solta Palavra, v. 19, p. 17-24, abr. 2013.

SARMENTO, M. S. Ecolexicography: words and expressions we should live by. In Österreichische Linguistiktagung 2000. 30 Jahre Sprache und Ökologie. Graz: Graz Universität, 2000.

Ecolexicography: ecological and unecological words and expressions. In: FILL, A.; PENZ; H; TRAMPE, W. (ed.) Colourful Green Ideas. Viena: Peter Lang Verlag, 2002. p. 487-492.

Por uma ecolexicografia. Confluências, v. 2, p. 84-97, Mai. 2005.

$\overline{\mathrm{STIBBE}}, \mathrm{A}$. Animals Erased: Discourse, Ecology, and Reconnection With the Natural World. Middletown, CT: Wesleyan University Press, 2012. 


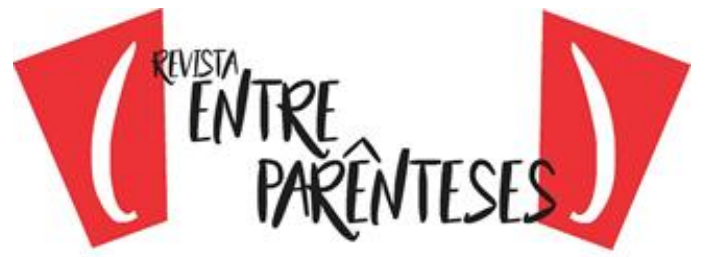

. Ecolinguistics: Language, Ecology and the Stories We Live By. London: Routledge, 2015.

SVÉNSEN, B. A Handbook of Lexicography. The Theory and Practice of DictionaryMaking. Cambridge: CUP, 2009.

TRAMPE, W. Language and Ecological Crisis. Extracts from a Dictionary of Industrial Agriculture. In: FILL, A.; MÜHLHÄUSLER, P. (ed.). The Ecolinguistics Reader. Language, ecology, and environment. Londres: Continuum, 2001, p.232-240.

. Euphemisms for Killing Animals and for Other Forms of Their Use. In: FILL, A.; PENZ; H. (ed.). The Routledge Handbook of Ecolinguistics. Londres: Routledge, 2017. p. 325-341.

WELKER, H. A. Dicionários. Uma pequena introdução à lexicografia. Brasília: Thesaurus, 2004.

\section{APÊNDICE \\ EXEMPLO DE UM VERBETE ECOLEXICOGRÁFICO}

so.lo s.m.

\section{DEFINIÇÃO}

1. Fina camada de superfície terrestre, constituída de rochas e partículas minerais, misturada com matéria orgânica em que vivem e dependem todos os seres vivos de nosso planera, o planeta Terra. 2. O ser humano por apresentar um domínio, interesse e óbvia afinidade com o solo formula vários outros conceitos para o solo, como: país, terreno, chão, trechos ou tipos específicos de terra, entre outros.

ABONAÇÃO

"A poluição do solo, ou seja, a camada superficial da crosta terrestre ocorre por diversos fatores relacionados à ocupação e exploração do meio ambiente." "Este é o solo de nosso país."

\section{EFEITOS}

$E C$, criativo, local onde plantas e animais nascem, crescem, desenvolvem-se, evoluem, morrem e retiram seus respectivos alimentos e matérias primas para uso; EM, mantenedor, camada em que os seres encontram sustentação, segurança, abrigo e retiram seus alimentos; EE, enfraquecedor, uso abusivo do solo, como em 


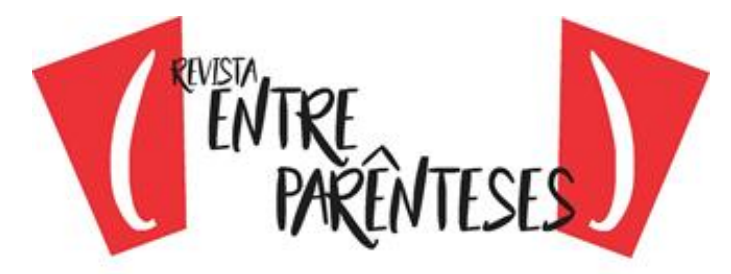

monoculturas, desvio de curso d'águas para irrigação, que pode causar desertificação, e retirada em excesso de árvores e demais plantas, que pode causar, além do enfraquecimento do solo, a erosão; $E D$, destrutivo, a erosão tem relação com este efeito a depender de sua magnitude, além deste há os processos de queimada, escavações para diversos fins (extrativismo mineral e vegetal, pesquisas etc.); atividades tectônicas, como terremotos, maremotos, vulcões, entre outros, que podem ter relação ou não com o impacto negativo da atividade humana, mas seus resultados podem ser destrutivos para o próprio solo e para toda a natureza.

RESULTADOS

O solo pode ser pensado desde um binário de opostos até um ternário de confluências, já que nele verificamos sua fertilidade, o que possibilita tanto características positivas para o próprio solo, quanto para a manutenção dos seres vivos, em oposição ao solo desgastado, danificado ou destruído seja pela ação do ser humano ou pela natureza, o que pode reduzir a vida ou até mesmo extingui-la, tornando o solo inabitável (lógica formal). Numa visão dialética, percebemos que o solo ao mesmo tempo que fornece elementos para a sustentação da vida também pode causar a morte de seres vivos, porém a morte de seres vivos é necessário, pois o solo acaba extrair os nutrientes dos cadáveres, gerando, assim, mais elementos para os demais seres vivos, ocorrendo um ciclo de nascimento, morte e manutenção.

Recebido em 01/10/2018.

Aceito em 26/12/2018. 